02

\title{
Одиночные центры и димеры примесных ионов гольмия в кристаллах синтетического форстерита: спектроскопия высокого разрешения
}

\author{
(C) Е.П. Чукалина ${ }^{1}$, И.О. Тюренков ${ }^{2}$, Е.В. Жариков ${ }^{3}$, К.А. Субботин ${ }^{3}$ \\ ${ }^{1}$ Институт спектроскопии РАН, \\ 108840 Троицк, Москва, Россия \\ ${ }^{2}$ Московский физико-технический институт (национальный исследовательский университет), \\ 141700 Долгопрудный, Московская обл., Россия \\ ${ }^{3}$ Институт общей физики им. А.М. Прохорова РАН, \\ 119991 Москва, Россия \\ e-mail: echukalina@isan.troitsk.ru
}

Поступила в редакцию 25.02.2019 г.

В окончательной редакции 25.02.2019 г.

Принята к публикации 15.03.2019 г.

\begin{abstract}
Зарегистрированы низкотемпературные спектры поглощения с высоким спектральным разрешением в области переходов ${ }^{5} I_{8} \rightarrow{ }^{5} I_{7,6,5,4},{ }^{5} F_{5}$ в примесном ионе $\mathrm{Ho}^{3+}$ в кристалле синтетического форстерита $\mathrm{Mg}_{2} \mathrm{SiO}_{4}$. Сравнение наблюдаемой формы спектральных линий и вычисленной по теории кристаллического поля сверхтонкой структуры позволило впервые идентифицировать спектральные линии по принадлежности к одиночным центрам и димерам.
\end{abstract}

Ключевые слова: кристалл форстерита, ионы гольмия, спектры поглощения

DOI: $10.21883 /$ OS.2019.07.47927.83-19

\section{Введение}

В настоящее время существенный интерес исследователей в мире обращен к проблемам квантовой информатики, актуальными направлениями которой являются квантовые вычисления и квантовая память. Максимальная плотность записи информации достижима для твердотельных систем, среди которых значительное внимание уделяется диэлектрическим кристаллам с редкоземельными (Р3) ионами [1-4]. В данное время наилучшие результаты по реализации оптической квантовой памяти достигнуты на кристаллах ортосиликата иттрия $\mathrm{Y}_{2} \mathrm{SiO}_{5}$, содержащего различные Р3 ионы: $\operatorname{Pr}^{3+}[5], \mathrm{Eu}^{3+}$ [6], $\mathrm{Er}^{3+}[7,8], \mathrm{Nd}^{3+}$ [9]. Кристаллы другого силиката, синтетического форстерита $\mathrm{Mg}_{2} \mathrm{SiO}_{4}$, легированного Р3 ионами, также рассматриваются в качестве материала для квантовой памяти [10]. Одним из важных преимуществ форстерита является то, что для основной части стабильных изотопов магния и кислорода ядерный спин равен нулю. Ненулевые ядерные спины имеют только изотопы ${ }^{17} \mathrm{O},{ }^{29} \mathrm{Si}$ и ${ }^{25} \mathrm{Mg}$ с естественной распространенностью $0.04,4.6$ и 10\% соответственно. Флуктуация магнитного поля, создаваемого ядерными спинами кристаллической матрицы, является одним из основных факторов, укорачивающих время когерентности электронно-ядерных состояний. Еще одна особенность Р3 центров в форстерите может оказаться благоприятной для увеличения времени когерентности. А именно для кристаллов форстерита $\mathrm{Mg}_{2} \mathrm{SiO}_{4}$, легированных ионами $\mathrm{Ho}^{3+}[11,12], \mathrm{Tb}^{3+}[13], \mathrm{Yb}^{3+}[10]$, $\mathrm{Er}^{3+}[14]$, методом электронного парамагнитного резо- нанса (ЭПР) обнаружена высокая степень самоорганизации трехвалентных Р3 ионов в димеры. При этом известно, что реализовать большое время сохранения когерентности возможно с использованием димеров Р3 ионов в сложных молекулярных системах [4].

В связи с перспективой применений форстеритов с P3 ионами в квантовых технологиях актуальной задачей становится изучение различных примесных Р3 центров и сверхтонкой структуры (СТС) штарковских уровней P3 ионов в форстеритах. Недавно мы сообщили о первом наблюдении СТС в оптических спектрах синтетического форстерита, легированного гольмием [15]. Полученные экспериментальные данные были подтверждены расчетом по теории кристаллического поля [15]. Настоящая работа является продолжением начатого нами исследования спектров поглощения кристаллов $\mathrm{Mg}_{2} \mathrm{SiO}_{4}: \mathrm{Ho}^{3+}$ с высоким спектральным разрешением. В ней мы покажем, как на основе информации о СТС возможно указать принадлежность линий поглощения к определенному типу примесного гольмиевого центра в синтетическом форстерите. Насколько известно авторам, подобное исследование проведено впервые.

\section{Кристаллическая структура и примесные Р3 центры в форстерите}

Кристаллическая решетка форстерита $\mathrm{Mg}_{2} \mathrm{SiO}_{4}$, относящегося к семейству оливина, имеет ромбическую симметрию с пространственной группой $D_{2 h}^{16}$ (Pbnm). Структура форстерита состоит из гексагональной плот- 
ной упаковки атомов кислорода, в которой половина октаэдрических пустот занята ионами $\mathrm{Mg}^{2+}$ в двух кристаллографически неэквивалентных позициях (MI и M2). Позиция M1 имеет триклинную симметрию c точечной группой $C_{i}$. Для позиции $M 2$ характерно наличие зеркальной плоскости симметрии, перпендикулярной оси $c$ (точечная группа симметрии $C_{s}$ ). Октаэдры $\mathrm{MgO}_{6}$ не имеют общих граней, а соединены тетраэдрами, в каждом восьмом из которых находится ион $\mathrm{Si}^{4+}$. Вследствие кулоновского отталкивания ионов $\mathrm{Mg}^{2+}$ в цепочке [16] все полиэдры в $\mathrm{Mg}_{2} \mathrm{SiO}_{4}$ искажены. При легировании форстерита редкими землями трехвалентные примесные Р3 ионы замещают двухвалентные ионы магния [10-14]. Подобное гетеровалентное замещение возможно при наличии компенсатора избыточного катионного заряда. В качестве такого компенсатора служат магниевые вакансии. Р3 ион может быть локализован в магниевой позиции (одиночный центр) или образовывать димерный центр из двух Р3 ионов и магниевой вакансии. Концентрация димеров превышает на несколько порядков уровень, определенный при условии статистического распределения примесных Р3 ионов по узлам кристаллической решетки [10-14]. Этот результат подтверждается компьютерным моделированием кластерных центров иттербия в $\mathrm{Mg}_{2} \mathrm{SiO}_{4}$ методом межатомных потенциалов [10]. В работе [10] показано, что при образовании димеров имеет место минимально возможное увеличение внутренней энергии кристаллической решетки.

Структура примесных центров ионов гольмия в кристаллах $\mathrm{Mg}_{2} \mathrm{SiO}_{4}: \mathrm{Ho}^{3+}$ изучена методом высокочастотной и стандартной спектроскопии ЭПР $[11,12]$, оптическими исследованиями и сравнением экспериментальных данных с расчетом по теории кристаллического поля [12]. Ионы $\mathrm{Ho}^{3+}$ замещают ионы $\mathrm{Mg}^{2+}$ в позициях $M 2$, образуя одиночные центры и димеры. Димеры состоят из двух ионов $\mathrm{Ho}^{3+}$ с магниевой вакансией между ними $[11,12]$. Применение метода селективного лазерного возбуждения люминесценции кристаллов $\mathrm{Mg}_{2} \mathrm{SiO}_{4}: \mathrm{Ho}^{3+}$ не позволило однозначно приписать оптические переходы определенным примесным центрам ионов $\mathrm{Ho}^{3+}[17]$.

\section{Образцы и экспериментальный метод}

Исследуемый кристалл выращен методом Чохральского из иридиевого тигля в атмосфере технического азота на затравку, вырезанную из монокристалла номинально чистого форстерита вдоль кристаллографической оси $a$ (установка Pbnm). Скорость вытягивания на номинальной стадии роста составляла $0.7 \mathrm{~mm} / \mathrm{h}$, скорость вращения - $6 \mathrm{rpm}$. Для уменьшения последствий концентрационного переохлаждения применялась конфигурация тепловых экранов, увеличивающая осевой температурный градиент в зоне кристаллизации. В качестве исходных реактивов использовались $\mathrm{MgO}, \mathrm{SiO}_{2}$ и $\mathrm{Ho}_{2} \mathrm{O}_{3}$

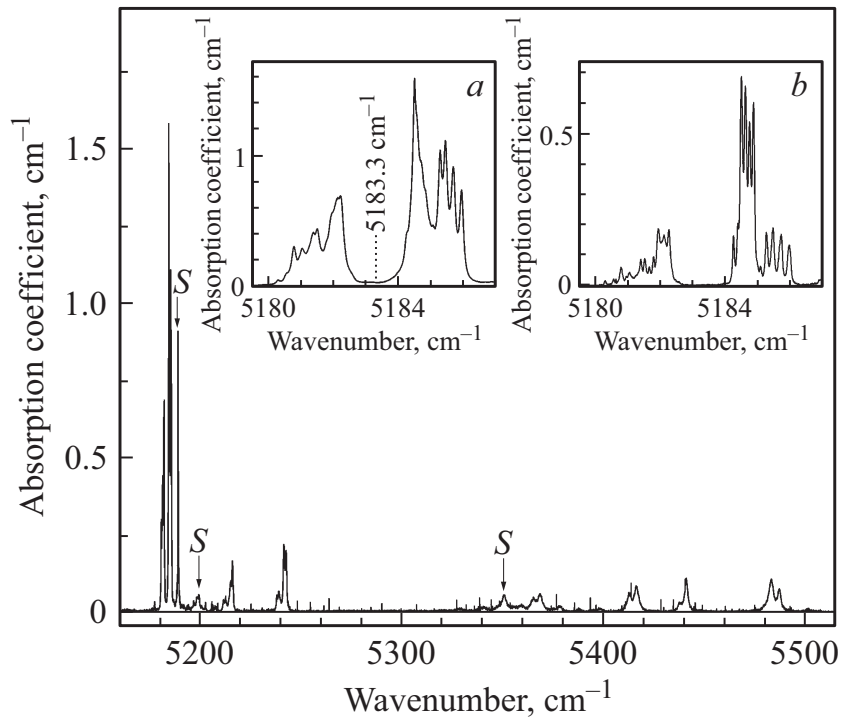

Pис. 1. Спектры поглощения в области перехода ${ }^{5} I_{8} \rightarrow{ }^{5} I_{7}$ в ионах $\mathrm{Ho}^{3+}$ в кристалле $\mathrm{Mg}_{2} \mathrm{SiO}_{4}: \mathrm{Ho}^{3+}$ (0.13 at.\%) при $T=5 \mathrm{~K}$. Заглавной латинской буквой , $S^{\text {“ }}$ обозначены спектральные линии, относящиеся к иону $\mathrm{Ho}^{3+}$ в одиночном центре. На вставке $a$ показана подробно линия с разрешенной СТС, соответствующая переходу из основного квазидублета на первый возбужденный квазидублет мультиплета ${ }^{5} I_{7}$ иона $\mathrm{Ho}^{3+}$ в димере (отмечена средняя частота $5183.3 \mathrm{~cm}^{-1}$ этой линии). На вставке $b$ эта же линия приведена для образца № 1 [15]. Очень узкие линии - поглощение парами воды.

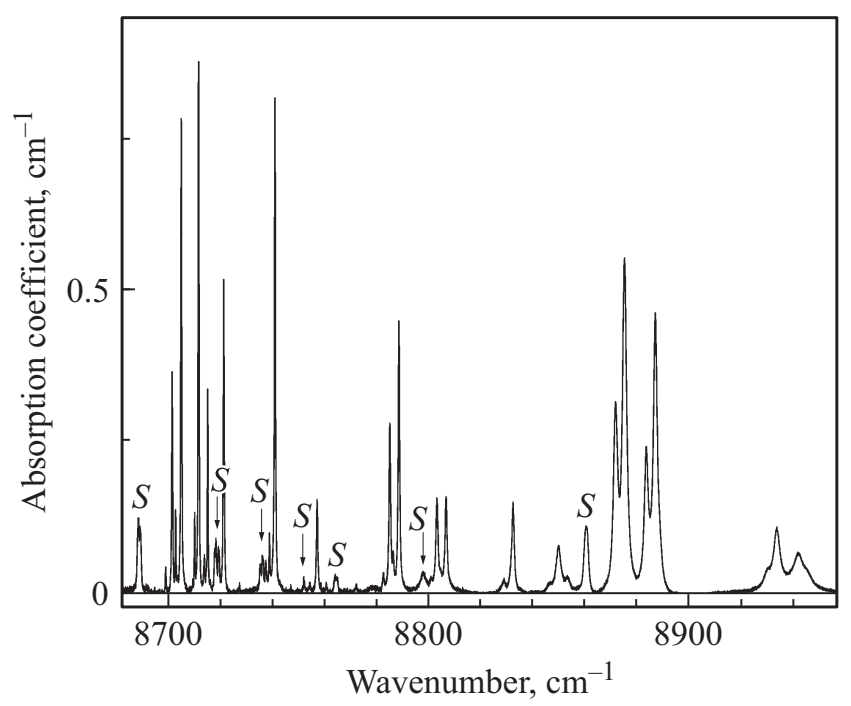

Рис. 2. Спектры поглощения в области перехода ${ }^{5} I_{8} \rightarrow{ }^{5} I_{6}$ в ионах $\mathrm{Ho}^{3+}$ в кристалле $\mathrm{Mg}_{2} \mathrm{SiO}_{4}: \mathrm{Ho}^{3+}$ (0.13 at.\%) при $T=5 \mathrm{~K}$. Заглавной латинской буквой , $S^{6}$ обозначены спектральные линии, относящиеся к иону $\mathrm{Ho}^{3+}$ в одиночном центре.

квалификации „ОСЧ“. Активатор вводился в шихту в количестве 11.7 wt.\% с эквимолярной компенсацией $\mathrm{SiO}_{2}$. Концентрация ионов $\mathrm{Ho}^{3+}$ в кристалле была измерена с помощью рентгено-спектрального микроанализа в ше- 


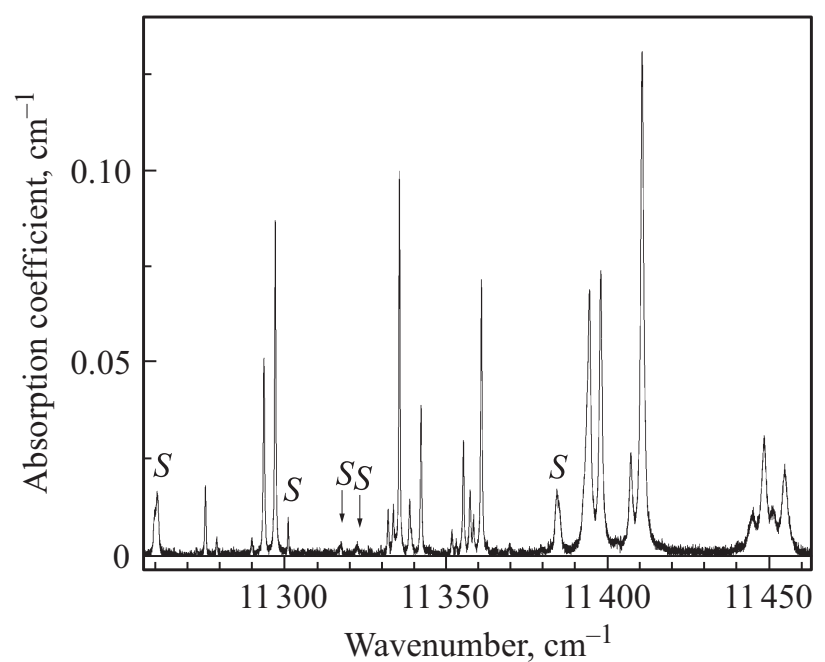

Pис. 3. Спектры поглощения в области перехода ${ }^{5} I_{8} \rightarrow{ }^{5} I_{5}$ в ионах $\mathrm{Ho}^{3+}$ в кристалле $\mathrm{Mg}_{2} \mathrm{SiO}_{4}: \mathrm{Ho}^{3+}$ (0.13 at.\%) при $T=5 \mathrm{~K}$. Заглавной латинской буквой „S“ обозначены спектральные линии, относящиеся к иону $\mathrm{Ho}^{3+}$ в одиночном центре.

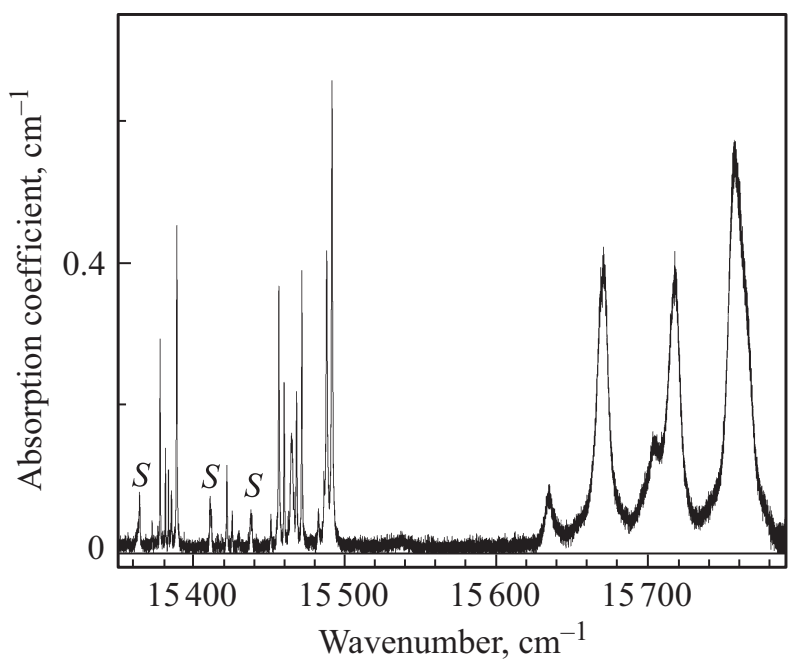

Pис. 4. Спектры поглощения в области перехода ${ }^{5} I_{8} \rightarrow{ }^{5} F_{5}$ в ионах $\mathrm{Ho}^{3+}$ в кристалле $\mathrm{Mg}_{2} \mathrm{SiO}_{4}: \mathrm{Ho}^{3+}(0.13$ at.\%) при $T=5 \mathrm{~K}$. Заглавной латинской буквой „S“ обозначены спектральные линии, относящиеся к иону $\mathrm{Ho}^{3+}$ в одиночном центре.

сти разных точках шлифа образца и оказалась равной $0.13 \pm 0.01$ at. $\%$.

Оптически прозрачный образец монокристалла $\mathrm{Mg}_{2} \mathrm{SiO}_{4}: \mathrm{Ho}^{3+}(0.13$ at.\%) имел форму, близкую к цилиндрической, с диаметром около $5 \mathrm{~mm}$ и длиной $18 \mathrm{~mm}$. Спектры пропускания образца зарегистрированы при температурах 5-20 K в спектральной области $4000-16000 \mathrm{~cm}^{-1}$ с разрешением вплоть до $0.01 \mathrm{~cm}^{-1} \mathrm{c}$ помощью вакуумного фурье-спектрометра высокого разрешения Bruker IFS 125HR. При регистрации спектров с высоким разрешением в области $5150-5550 \mathrm{~cm}^{-1}$ наблюдаются слабые линии поглощения остаточных паров воды. Низкотемпературные измерения проведены с использованием оптического криостата замкнутого цикла Cryomech ST430. Излучение источника не было поляризовано. Образец устанавливался в криостате таким образом, что свет проходил вдоль оси $a$.

\section{Результаты и обсуждение}

На рис. 1-4 изображены спектры поглощения при температуре $T=5 \mathrm{~K}$ в области перехода из основного состояния ${ }^{5} I_{8}$ иона $\mathrm{Ho}^{3+}$ на возбужденные мультиплеты: ${ }^{5} I_{7}$ (рис. 1), ${ }^{5} I_{6}$ (рис. 2), ${ }^{5} I_{5}$ (рис. 3) и ${ }^{5} F_{5}$ (рис. 4). Следует заметить, что в ближней инфракрасной области спектра переходы ${ }^{5} I_{8} \rightarrow{ }^{5} I_{5,4}$ в ионе $\mathrm{Ho}^{3+}$ являются наименее интенсивными. Зарегистрировать их, используя образец, исследованный нами в предыдущей работе [15], не удалось. Для этого кристалла, обозначенного как образец № 1, концентрация легирующий примеси $\mathrm{Ho}_{2} \mathrm{O}_{3}$ в расплаве была $2.3 \mathrm{wt} \%$. Концентрация ионов $\mathrm{Ho}^{3+}$ в выращенном кристалле, согласно оценке, приведенной в работе [11], не превышала 0.1 wt.\%. Сравнивая спектры поглощения двух кристаллов с разными концентрациями гольмия, мы провели оценку концентрации ионов $\mathrm{Ho}^{3+}$ в образце № 1. Эта величина составила 0.02 at.\%. Увеличение концентрации примесных ионов $\mathrm{Ho}^{3+}$ в кристалле $\mathrm{Mg}_{2} \mathrm{SiO}_{4}$ приводит к уширению спектральных линий. Новых линий при этом в спектре не появляется. На вставках к рис. 1 приведена линия с разрешенной СТС для двух образцов: (a) $\mathrm{Mg}_{2} \mathrm{SiO}_{4}: \mathrm{Ho}^{3+}$ (0.13 at.\%) и $(b)$ образец № 1. Полуширина отдельной компоненты СТС линии в спектре поглощения образца № 1 равна $0.1 \mathrm{~cm}^{-1}$, а кристалла $\mathrm{Mg}_{2} \mathrm{SiO}_{4}: \mathrm{Ho}^{3+}(0.13$ at.\%) $0.15 \mathrm{~cm}^{-1}$. Каждый из спектров, представленных на рис. $1-4$, включает линии поглощения, соответствующие переходам в ионах $\mathrm{Ho}^{3+}$ как в одиночных центрах, так и в димерах. Провести отнесение оптических линий к определенным примесным центрам гольмия исключительно на основе полученных нами экспериментальных данных не представляется возможным. Поэтому мы прибегли к помощи расчета по теории кристаллического поля, проведенного ранее в работах $[12,15]$. Симметрия кристаллографической позиции $M 2$ описывается точечной группой $C_{s}$. Кристаллическое поле такой симметрии расщепляет $(2 J+1)$-кратно вырожденные уровни ${ }^{2 S+1} L_{J}$ свободного иона $\mathrm{Ho}^{3+}$ на синглеты $\Gamma_{1}$ и $\Gamma_{2}$, не имеющие СТС в первом приближении. По данным ЭПР [12] основное состояние иона $\mathrm{Ho}^{3+}$ как для одиночного центра, так и для димера является квазидублетом. В случае одиночного центра расстояние между двумя синглетными уровнями основного состояния иона $\mathrm{Ho}^{3+}$ равно $0.23 \mathrm{~cm}^{-1}(7 \mathrm{GHz})$ [12] и для димера $-3.43 \mathrm{~cm}^{-1}$ $(103 \mathrm{GHz})[12]$. Третий уровень основного мультиплета ${ }^{5} I_{8}$ иона $\mathrm{Ho}^{3+}$ по расчету, согласующемуся с данными ЭПР [11,12], имеет энергию для одиночных центров $78.5 \mathrm{~cm}^{-1}$ и для димеров $44.7 \mathrm{~cm}^{-1}$. Теоретический 

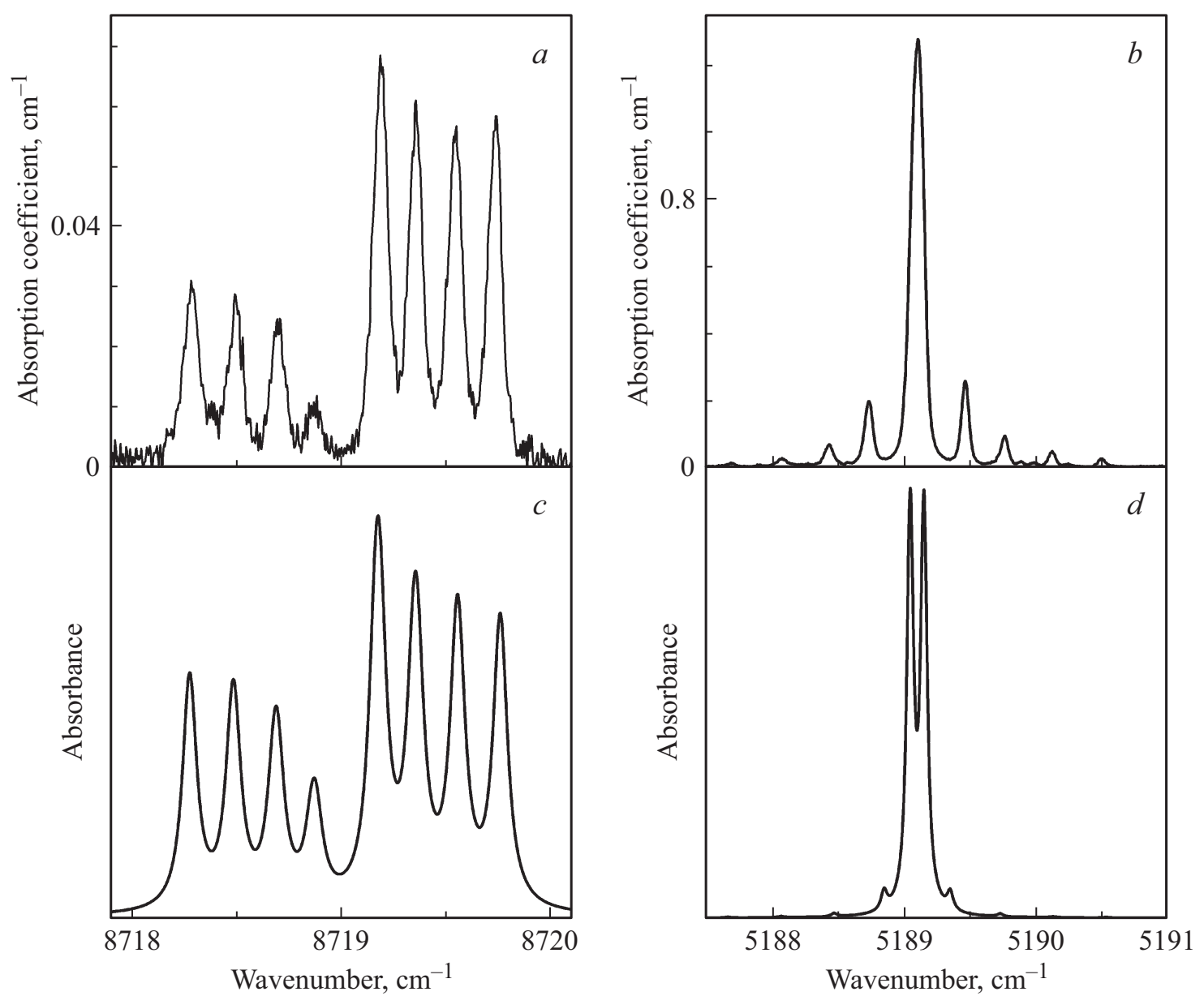

Рис. 5. Экспериментальная $(a, b)$ и вычисленная $(c, d)$ СТС спектральных линий, относящихся к иону Но ${ }^{3+}$ в одиночном центре. Линия поглощения, соответствующая переходу из основного квазидублета на синглетный уровень возбужденного мультиплета ${ }^{5} I_{6}(a, c)$; линия поглощения, соответствующая переходу из основного квазидублета на первый квазидублет возбужденного мультиплета ${ }^{5} I_{7}(b, d)$. Экспериментальные спектры $(a, b)$ зарегистрированы для образца № 1 [15].

Таблица 1. Теоретически вычисленные значения энергий сверхтонких подуровней $\left(\mathrm{cm}^{-1}\right)$ основного квазидублета иона $\mathrm{Ho}^{3+}$ в одиночном центре $\left(E_{s}\right)$ и димере $\left(E_{d}\right)$

\begin{tabular}{c|c|c|c|c|c|c|c|c}
\hline $\begin{array}{c}\text { Номер } \\
\text { уровня }\end{array}$ & 1 & 2 & 3 & 4 & 5 & 6 & 7 & 8 \\
\hline$E_{s}$ & 0 & 0.21 & 0.41 & 0.59 & 0.90 & 1.08 & 1.29 & 1.49 \\
$E_{d}$ & 0 & 0.07 & 0.11 & 0.13 & 3.68 & 3.71 & 3.75 & 3.82
\end{tabular}

расчет СТС квазидублетов иона $\mathrm{Ho}^{3+}$ проводился в приближении магнитодипольного сверхтонкого взаимодействия [15]. Вычисленная СТС квазидублета состоит из восьми сверхтонких подуровней, каждый из которых остается дважды вырожденным в отсутствие магнитного поля. Восемь сверхтонких подуровней разделены на две группы, состоящие из четырех неэквидистантных подуровней, разделенных щелью. Величина этой щели зависит от начального расщепления квазидублета и силы сверхтонкого взаимодействия. В табл. 1 приведены вычисленные значения энергий сверхтонких подуровней основного квазидублета иона $\mathrm{Ho}^{3+}$ в одиночном центре и димере.

Рассмотрим СТС линий, соответствующих переходам в ионе $\mathrm{Ho}^{3+}$ в одиночных центрах. На рис. 5 представлены экспериментальный $(a)$ и вычисленный спектр $(c)$ в случае перехода из основного квазидублета на синглетный уровень возбужденного мультиплета ${ }^{5} I_{6}$ в ионе $\mathrm{Ho}^{3+}$. СТС такой линии по сути отражает структуру сверхтонких подуровней основного квазидублета. В случае, когда возбужденное состояние является квазидублетом, СТС линий будет иметь более сложную форму. В качестве примера на рис. $5, b, d$ изображена линия с СТС, также относящаяся к иону $\mathrm{Ho}^{3+}$ в одиночном центре: $(b)$ экспериментальный, $(d)$ вычисленный спектр. Необычная форма СТС линии обусловлена спектрально разделенными электро- и магнитодипольными вкладами. Как правило, магнитодипольные переходы существенно слабее. Тот факт, что они наблюдаются в области перехода ${ }^{5} I_{8} \rightarrow{ }^{5} I_{7}$, объясняется тем, что этот 
переход в свободном ионе $\mathrm{Ho}^{3+}$ разрешен как магнитодипольный. Спектральная линия с подобной СТС наблюдалась ранее в спектрах пропускания кристаллов $\mathrm{LiYF}_{4}$-Ho [18].

На рис. 6, $a, b$ представлены линии поглощения димеpa: $(a)$ линия поглощения, соответствующая переходу из основного квазидублета на синглетный уровень возбужденного мультиплета ${ }^{5} I_{6}$ при температурах 5 и $15 \mathrm{~K}$, (b) линия поглощения, соответствующая переходу из основного квазидублета на квазидублет возбужденного мультиплета ${ }^{5} I_{7}$ при температурах 5 и $15 \mathrm{~K}$. На pис. $6, c, d$ приведены вычисленные спектры: $(c)$ в случае перехода из основного квазидублета на возбужденный синглет, $(d)$ в случае перехода из основного квазидублета на возбужденный квазидублет. Форма линий, изображенных на рис. $6, a, b$, обусловлена неразрешенной СТС. В отличие, например, от линии с хорошо разрешенной CTC, приведенной на вставке $(b)$ к рис. 1, которая так же как и линия, изображенная на рис. $6, b$, соответствует переходу из основного квазидублета на возбужденный квазидублет иона $\mathrm{Ho}^{3+}$ в димере. Сделать вывод о принадлежности линий, показанных на рис. $6, a, b$, к димеру возможно из анализа температурной зависимости спектров. Сравнение спектров, зарегистрированных при двух температурах, 5 и $15 \mathrm{~K}$ (рис. 6, $a, b$ ), показывает наличие компоненты спектральной линии, интенсивность которой уменьшается при понижении температуры в соответствии с законом Больцмана. Эта компонента отстоит от основной линии на $3.5 \mathrm{~cm}^{-1}$, что соответствует расстоянию между центрами двух групп из четырех неэквидистантных сверхтонких подуровней основного квазидублета иона $\mathrm{Ho}^{3+}$, находящегося в позиции M2 димера. Согласно расчету, эта величина составляет $3.7 \mathrm{~cm}^{-1}$ (табл. 1). Соответствие формы линий поглощения, экспериментально наблюдаемых (рис. 6, $a, b$ ) и теоретически вычисленных (рис. 6, $c, d$ ), подтверждает отнесение этих линий к димерам. Проделывая аналогичную процедуру сравнения формы линий поглощения в экспериментальном спектре с теоретическим расчетом СТС линий для примесных ионов гольмия в форстерите, мы разделили практически все спектральные линии по принадлежности к одиночному гольмиевому центру и димеру. Исключение составляют линии в высокочастотной части оптических переходов ${ }^{5} I_{8} \rightarrow{ }^{5} I_{5},{ }^{5} F_{5}$, уширенные вследствие электронфононного взаимодействия. Результат представлен в табл. 2. Используя полученные спектроскопические данные, мы оценили отношение интегральных интенсивностей оптических переходов в ионах $\mathrm{Ho}^{3+}$ для одиночных позиций и димеров. Из этой оценки следует, что число димеров превосходит на порядок число одиночных центров примесных ионов $\mathrm{Ho}^{3+}$ в форстерите $\mathrm{Mg}_{2} \mathrm{SiO}_{4}-\mathrm{Ho}$. Это подтверждают выводы, сделанные из проведенных ранее исследований $[11,12]$.

Кроме того, мы обнаружили в спектрах слабые линии, которые почти всегда сопровождали линии, отнесенные к димеру, но имели расстояние между компонентами
Таблица 2. Средние частоты линий с СТС в спектрах ионов $\mathrm{Ho}^{3+}$ в одиночных центрах $E_{S}$ и димерах $E_{D}$ при $T=5 \mathrm{~K}$. Звездочками * обозначены линии, соответствующие переходам из основного состояния на квазидублеты возбужденных мультиплетов

\begin{tabular}{|c|c|c|}
\hline${ }^{2 S+1} L_{J}$ & $E_{S}, \mathrm{~cm}^{-1}$ & $E_{D}, \mathrm{~cm}^{-1}$ \\
\hline${ }^{5} I_{7}$ & $\begin{array}{l}5189.1^{*} \\
5199.1 \\
5350.8\end{array}$ & $\begin{array}{l}5183.3^{*} \\
5213.8^{*} \\
5240.4 \\
5367.2 \\
5415.4^{*} \\
5439.7 \\
5485.6\end{array}$ \\
\hline${ }^{5} I_{6}$ & $\begin{array}{l}8688.9 \\
8719 \\
8735.9 \\
8751.9 \\
8764.2 \\
8798 \\
8860.4\end{array}$ & $\begin{array}{l}8703.2 \\
8713.3 \\
8719.6 \\
8739.2 \\
8757.1 \\
8786.8 \\
8805.6 \\
8830.4 \\
8851.6 \\
8873.3 \\
8885.5 \\
8931.9 \\
8943.9\end{array}$ \\
\hline${ }^{5} I_{5}$ & $\begin{array}{l}11260.8 \\
11299.6 \\
11317.1 \\
11322.6 \\
11384.3\end{array}$ & $\begin{array}{l}11277.7 \\
11295.6 \\
11333.9 \\
11340.5 \\
11353.4 \\
11358.9 \\
11395.8 \\
11408.3 \\
11445.5 \\
11452.1\end{array}$ \\
\hline${ }^{5} I_{4}$ & & $\begin{array}{l}13285.1 \\
13321.4 \\
13335.1 \\
13367.4\end{array}$ \\
\hline${ }^{5} F_{5}$ & $\begin{array}{l}15364.1 \\
15411.4 \\
15416.1 \\
15429.8 \\
15438.1 \\
15464.7\end{array}$ & $\begin{array}{l}15379.9 \\
153.87 .1 \\
15423.8 \\
15457.8 \\
15469.6 \\
15484.1 \\
15489.4\end{array}$ \\
\hline
\end{tabular}

не $3.5 \mathrm{~cm}^{-1}$, а $3.8 \mathrm{~cm}^{-1}$. Возможно, они относятся к другому типу димера. Выяснение структуры этого центра вопрос будущих исследований.

Недавно методом стандартной ЭПР-спектроскопии в $X$ - и $Q$-диапазонах установлено, что ионы $\mathrm{Yb}^{3+}[10]$ и $\mathrm{Er}^{3+}[14]$ в синтетическом форстерите замещают ионы магния в кристаллографической позиции $M 1$ в виде 

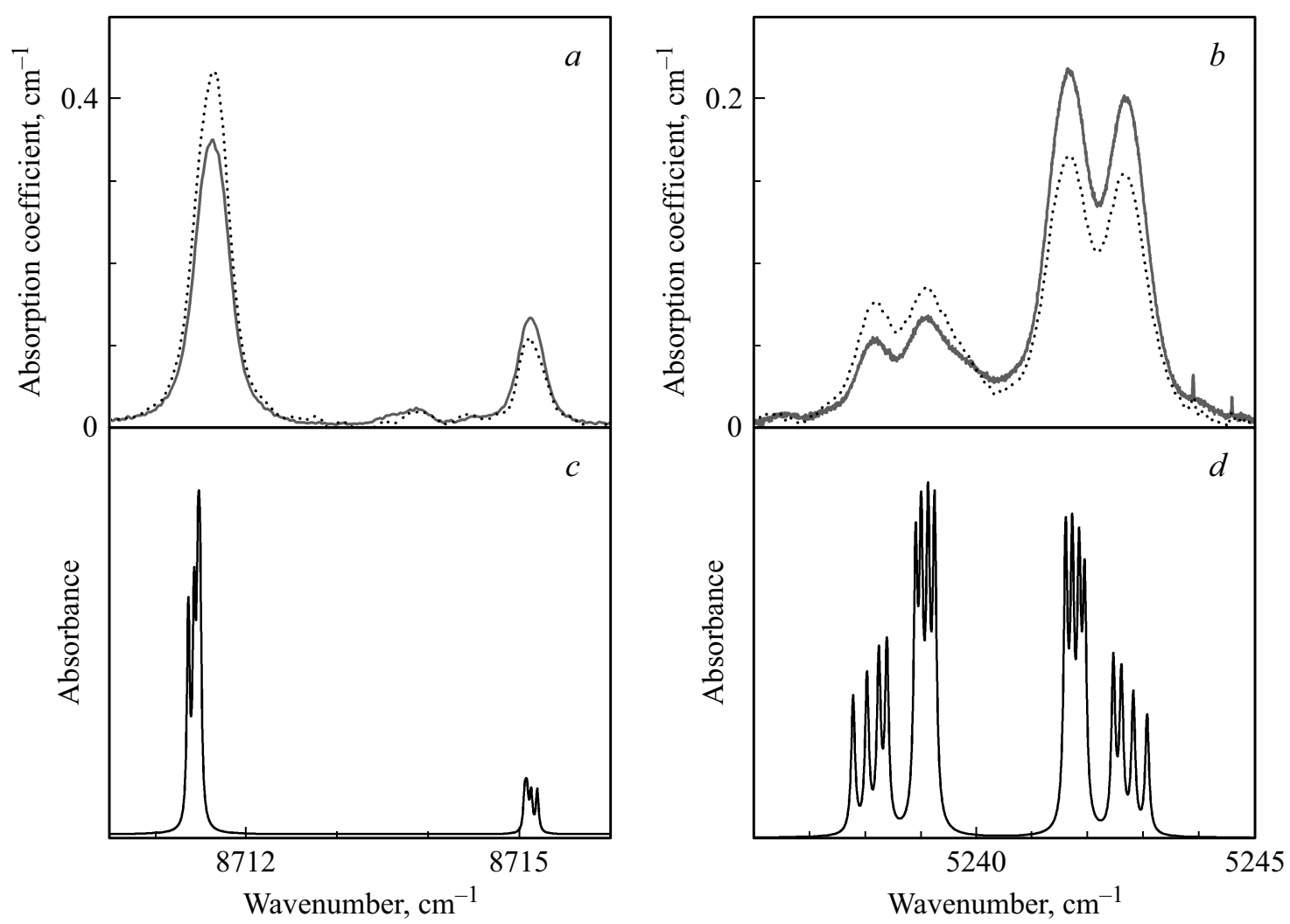

Рис. 6. Линии поглощения при температуре $T=5 \mathrm{~K}$ (серая линия) и $T=15 \mathrm{~K}$ (пунктирная линия) и вычисленная СТС спектральных линий, относящихся к иону $\mathrm{Ho}^{3+}$ в димере: $(a, c)$ для перехода из основного квазидублета на синглетный уровень возбужденного мультиплета ${ }^{5} I_{6} ;(b, d)$ для перехода из основного квазидублета на квазидублет возбужденного мультиплета ${ }^{5} I_{7}$. Экспериментальные спектры $(a, b)$ зарегистрированы для кристалла $\mathrm{Mg}_{2} \mathrm{SiO}_{4}: \mathrm{Ho}^{3+}(0.13$ at.\%).

одиночных ионов и димеров. В проведенном спектроскопическом исследовании кристаллов $\mathrm{Mg}_{2} \mathrm{SiO}_{4}: \mathrm{Ho}^{3+}$ не зарегистрировано проявление одиночных центров ионов $\mathrm{Ho}^{3+}$ в позиции $M 1$. Наличие центра инверсии для этой позиции приводит к запрету электродипольных $f-f$-переходов в Р3 ионе. Следовательно, линии одиночных центров иона $\mathrm{Ho}^{3+}$ в позиции $M 1$ могут наблюдаться только в области перехода ${ }^{5} I_{8} \rightarrow{ }^{5} I_{7}$, который магнитодипольно разрешен правилами отбора в свободном ионе $\mathrm{Ho}^{3+}$. Мы, напротив, наблюдали линии ионов $\mathrm{Ho}^{3+}$ в одиночных центрах во всей исследованной области спектра.

Таким образом, применение метода фурье-спектроскопии высокого разрешения совместно с расчетом по теории кристаллического поля продемонстрировало возможность по форме сверхтонкой структуры линий проводить идентификацию спектральных линий на предмет их отнесения к разным типам примесных центров в кристаллах.

\section{Заключение}

Используя данные о форме линий, полученные методом спектроскопии высокого разрешения, мы раз- делили спектры одиночных центров и димеров примесных ионов $\mathrm{Ho}^{3+}$ в синтетическом форстерите. Эти результаты, а также вычисленная СТС линий, хорошо согласующиеся с экспериментом, важны для возможных применений форстерита $\mathrm{Mg}_{2} \mathrm{SiO}_{4}: \mathrm{Ho}^{3+}$, в частности, для реализации оптической квантовой памяти.

\section{Благодарности}

Работа выполнена на Уникальной Научной Установке (УНУ) ИСАН „Мультифункциональная широкодиапазонная спектроскопия высокого разрешения“ (УНУ МШСВР ИСАН), http://www.ckp-rf.ru/usu/508571.

Авторы благодарны Б.3. Малкину за предоставленные программы расчета по теории кристаллического поля для примесного иона $\mathrm{Ho}^{3+}$ в форстерите и полезные обсуждения полученных результатов. Выражаем благодарность В.Ф. Тарасову за постоянный интерес к работе и ценные замечания, а также М.Н. Поповой и С.А. Климину за замечания по рукописи.

\section{Конфликт интересов}

Авторы заявляют, что у них нет конфликта интересов. 


\section{Список литературы}

[1] Rippe L., Nilsson M., Kröll S., Klieber R., Suter D. // Phys. Rev. 2005. V. 71. N 12. P 062328.

[2] Moiseev S.A., Tarasov V.F., Ham B.S. // J. Opt. B: Quantum Semiclass Opt. 2003. V. 5. P. 497.

[3] Bertaina S., Gambarelli S., Tkachuk A., Kurkin I.N., Malkin B., Stepanov A., Barbara B. // Nature Nanotechnology. 2007. V. 2. P. 39.

[4] Luis F., Repolles A., Martinez-Perez M.J., Aguila D., Roubeau O., Zueco D., Alonso P.J., Evangelisti M., Camon A., Sese J., Barrios L.A., Aromi G. // Phys. Rev. Lett. 2011. V. 107. P. 117203.

[5] Heinze G., Hubrich C., Halfmann T. // Phys. Rev. Lett. 2013. V. 111. P. 033601.

[6] Zhong M., Hedges M.P., Ahlefeldt R.L., Bartholomew J.G., Beavan S.E., Wittig S.M., Longdell J.J., Sellars M.J. // Nature. 2015. V. 517. P. 177.

[7] Probst S., Rotzinger H., Ustinov A.V., Bushev P.A. // Phys. Rev. 2015. V. 92. P. 014421.

[8] O'Brien C., Lauk N., Blum S., Morigi G., Fleischhauer M. // Phys. Rev. Lett. 2014. V. 113. P. 063603.

[9] Clausen C., Usmani I., Bussieres F., Sangouard N., Afzelius M., de Riedmatten H., Gisin N. // Nature. 2011. V. 469. P. 208.

[10] Тарасов В.Ф., Суханов А.А., Дудникова В.Б., Жариков Е.В., Лис Д.А., Субботин К.А. // Письма в ЖЭТФ. 2017. T. 106. № 2. C. 78.

[11] Гайстер А.В., Жариков Е.В., Коновалов А.А., Субботин К.А., Тарасов В.Ф. // Письма в ЖЭТФ. 2003. Т. 77. № 11. C. 753.

[12] Konovalov A.A., Lis D.A., Malkin B.Z., Nikitin S.I., Subbotin K.A., Tarasov V.F., Vorobieva E.N., Zharikov E.V., Zverev D.G. // Appl. Magn. Reson. 2005. V. 28. P. 267.

[13] Konovalov A.A., Lis D.A., Subbotin K.A., Tarasov V.F., Zharikov E.V. // Appl. Magn. Res. 2014. V. 45. P. 193.

[14] Зарипов Р.Б., Мингалиева Л.В., Тарасов В.Ф., Жариков Е.В., Субботин К.А., Лис Д.А. // ФТТ. 2019. Т. 61. № 2. C. 313 .

[15] Чукалина Е.П., Тюренков И.О., Жариков Е.В., Субботин К.А., Попова М.Н. // Письма в ЖЭТФ. 2019. Т. 109. № 6. C. 360 .

[16] Birle J.D., Gibbs G.V., Moore P.B., Smith J.V. // Amer. Mineralogist. 1968. V. 53. P. 807.

[17] Воробьева Е.Н., Лис Д.А., Малкин Б.З. // Тезисы Межд. науч. молодежной школы „Когерентная оптика и оптическая спектроскопия“. Казань, 2004. С. 397.

[18] Agladze N.I., Popova M.N. // Solid State Commun. 1985. V. 55. P. 1097. 